The Antecedents and Consequence of Et-Moone B2B Relationships

$$
\text { By }
$$

\author{
Ibrahim Abosag \\ SOAS, University of London \\ Department of Financial and Management Studies, \\ Thornhaugh Street, Russell Square, \\ London WC1H OXG \\ United Kingdom \\ Tel: 02078984223 \\ E-Mail: $\underline{\text { ia9@ } @ \text { soas.ac.uk }}$
}




\title{
The Antecedents and Consequence of Et-Moone B2B Relationships
}

\begin{abstract}
The literature from Eastern countries has well recognised the importance and influence of culturally specific constructs on business-to-business (B2B) relationships. With much of the literature largely focused on the Chinese Guanxi and its role in developing and maintaining $\mathrm{B} 2 \mathrm{~B}$, the expansion of $\mathrm{B} 2 \mathrm{~B}$ literature to other parts of the world has been limited. One important area of massive economic growth and influence is the Gulf region. Studies on B2B within the Gulf region are scarce. Over the last decade, exploratory studies on the Et-Moone relationships in the Gulf region identified significant impact on B2B relationships. Thus this paper builds up on recent exploratory studies on Et-Moone relationships. The paper examines the antecedents (interpersonal liking, trust and commitment) and consequence (cooperation) of Et-Moone relationships. Survey data were collected from over 180 senior managers in Saudi Arabia. The findings confirm the importance of Et-Moone in B2B relationships and its impact on cooperation. Implications for managers are discussed, and a guide for future research is provided.
\end{abstract}

Key words: Et-Moone, interpersonal liking, trust, commitment and cooperation, Saudi Arabia. 


\section{Introduction}

There has been growing literature on the special forms of Business-to-Business (B2B) relationships (e.g. Gaunxi, Blat, Et-Moone) in Eastern cultures (e.g. Michailova and Worm, 2003; Luo, 2007). The significance of these special forms of B2B is embedded in their ability to generate competitive advantage ( $\mathrm{Liu}, \mathrm{Li}$, Tao and Wang, 2008) and maintain strong relationships (Pimpa, 2008). Because these special forms of B2B relationships typically result in better cooperation and greater development of values for parties (e.g. Lohtia, Bello and Porter, 2009; Chen, Huang and Stemquist, 2011), it is imperative to further improve understandings in this area.

Drawing heavily on social exchange theory, our understanding on Eastern special forms of B2B that are sensitive to the cultural context, in which these relationships are embedded, has been strongly linked to our understanding of constructs such as trust, commitment and cooperation (e.g. Styles and Ambler, 2003; Zhuang, Xi and Tsang, 2010). One of these special forms of relationship that received growing attention is the Et-Moone relationship in the Middle East, mainly in Saudi Arabia (e.g. Abosag and Lee, 2012; Abosag and Naudé, 2014). While these studies have explored the Et-Moone relationship in B2B and examined its similarities and differences with the Chinese Guanxi, there has been no study that examined the key antecedents and consequences of the Et-Moone relationship. Thus, by examining the antecedents and consequences of Et-Moone, better theoretical insights can be gained.

According to Abosag and Lee (2012), Et-Moone is based on strong close and deep friendships that provide greater flexibility in business relationships and allow for unilateral decisions in business relationships without causing any uneasiness or division between partners. Interpersonal liking, trust and commitment in the relationship are key drivers of Et- 
Moone. The existence of Et-Moone in B2B relationships can lead to a higher level of cooperation through the development of greater synergy between competitive activities in the marketplace gaining even stronger advantages.

This study examines the key antecedents and consequences of Et-Moone in B2B relationships in Saudi Arabia. The key antecedents of Et-Moone are interpersonal liking, trust and commitment. The key outcome of Et-Moone is cooperation. Using survey data collected from over 180 senior managers of Saudi Arabian firms, the findings help expand our knowledge and understanding on B2B Et-Moone relationships, especially on the driving constructs of EtMoone in B2B relationships as well as its output. The paper starts by discussing the conceptual theoretical basis of the model and the hypotheses. It then reviews the methodological steps taken and presents the results from the analysis, making way for discussion of the findings and implications for managers and future studies.

\section{Et-Moone Relationships}

Et-Moone reflects a cultural system of relationships that exist in the Middle East at large and specifically in the Gulf States. Yet, the literature on business relationships within the Gulf States has been limited in number, especially when compared with the big economic and business growth in the Gulf. Academic studies on B2B in the Gulf can be traced back to the end of the last century, specifically the end of the 1990s. These rather few studies focused on market orientation in manufacturing (Bhuian, 1998), the relationship between satisfaction and relationship commitment in B2B (Abdul-Muhmin, 2002), and the determinants of relationship satisfaction and commitment in B2B (Abdul-Muhmin, 2005). More recently, Abosag and Lee (2012) provided a deep exploration of relationship development in the 
Middle East. Their study has been particularly useful in understanding Et-Moone and its effects on business relationships.

Since the social roots of Et-Moone have been discussed by Abosag and Lee (2012), the importance of Et-Moone in business relationships stems from its abilities to enable business partners to devote resources, support and commitment to each other as if their businesses were jointly owned by themselves. Thus, Et-Moone's partners are expected to make their businesses, resources and themselves as available as possible to each other, especially during difficult and challenging times in the marketplace (Abosag and Lee, 2012).

The term 'Et-Moone' is used by business partners to "express the importance of the relationship and to distinguish this relationship from other relationships" (Abosag and Naudé, 2014, p. 889). This expression of Et-Moone in the relationship often triggers a set of expectations that both sides of the relationship are aware of (but neither have discussed nor outlined in contracts) and are happy to commit to. Thus, the quality of interpersonal relationships is key to Et-Moone development. This is why only deep and long friendships and relationships can result in Et-Moone in business relationships, and partners are typically careful with whom to adopt Et-Moone. Having said this, Et-Moone is always reciprocal in expression and action and cannot exist from just one side of the relationship. However, EtMoone does not necessarily require reciprocities in doing favours. Meaning, unlike the Chinese Guanxi where favours are expected to be returned, Et-Moone partners are not conditioned to return favours unless it is necessary that they are returned (Abosag and Naudé, 2014). 
Furthermore, in order for business partners to develop Et-Moone, besides the long interaction and friendship, Abosag and Naudé (2014) found interpersonal liking and trust are essential to the development of Et-Moone. In addition, Abosag and Lee's (2012) exploration of EtMoone shows that relationship commitment is also an important antecedent for Et-Moone in a business relationship. According to Abosag and Lee (2012, p.608), these three constructs (interpersonal liking, commitment and trust) are the main antecedents of Et-Moone: "high commitment combined with total trust and high level of likability can lead to the development of an Et-Moone relationship." The following will discuss these antecedents as well as the output of Et-Moone.

\section{The Role of Interpersonal Liking}

Early literature on social exchange and marketing literature recognises interpersonal liking as the key element of interpersonal relationships (Zajonc, 1980; Crosby, Evansand Cowles 1990). Since then the literature on interpersonal liking did not pay attention to this construct until the seminal paper by Nicholson, Compeau and Sethi (2001) in which they argued that understanding the impact of interpersonal liking in B2B can help in developing deeper insights of B2B beyond traditional cognitive models. Their study was followed by an exploration of the construct by Hawke and Heffernan (2006) who defined interpersonal liking as "an ability to 'get on' or be comfortable with the other party in a bank lender-business customer relationship; based on a positive attitude each person has for the other and the recognition of the existence of an affirmative emotional connection" (p.152). Both studies (Nicholson et al., 2001; Hawke and Heffernan, 2006) found B2B relationship development highly influenced by the level of interpersonal liking that strengthens economic pledges and benefits. Recently, Abosag and Naudé (2014) found interpersonal liking to have the strongest influence on the special forms of relationships, namely Guanxi and Et-Moone. They argued 
that interpersonal liking is a prerequisite for Et-Moone in B2B, and without it Et-Moone relationships would not exist in $\mathrm{B} 2 \mathrm{~B}$ relationships. Thus, and following the findings from Abosag and Naudé (2014), we can hypothesise the following:

H1: interpersonal liking in B2B leads to Et-Moone relationships.

Aspects of interpersonal relationships have long been found to play a key role in B2B relationships (e.g. Dwyer, Schurr and Oh, 1987; Weitz and Jap, 1995; Wilson, 1995). Bilateral perception of personal interaction is important to the creation of trust (Zaheer, McEvily and Perrone, 1998), especially bilateral liking of the interaction (Thunman, 1992; Robbins and DeNisi, 1994). Importantly, interpersonal liking nurtures trust mutuality, which is essential to the development of special forms of relationships like Et-Moone. This relationship between interpersonal liking and trust has already been established (Nicholson $e t$ al., 2001). More recently, and within the context of Guanxi and Et-Moone relationships, Abosag and Naudé (2014) found interpersonal liking to have a big influence on trust in these relationships. Therefore:

H2: interpersonal liking increases trust in B2B relationships.

Although the link between interpersonal liking and trust was statistically established by Nicholson et al. (2001) and Abosag and Naudé (2014), the relationship between interpersonal liking and relationship commitment was also found to be significant by Harris, O’Malley and Patterson (2003). The findings by Hawke and Heffernan (2006, p.153) were most interesting as they found that "an increase in liking led to an increase in commitment." Thus the relationship between these two constructs is to some extent dependent on the ability to maintain mutual liking in the relationship. Because commitment is essential to the success of long-term B2B relationships (e.g. Morgan and Hunt, 1994), the ability to increase 
commitment through the increase in interpersonal liking, though not an easy task to maintain, is crucial to special forms of relationships such as Et-Moone relationships. Thus, it can be hypothesised that:

H3: interpersonal liking increases commitment in B2B relationships.

\section{Relationship Commitment and Et-Moone}

Relationship commitment has always been a key construct in B2B relationships (e.g. Morgan and Hunt, 1994; Gundlach, Achrol and Mentzer, 1995). Commitment is defined by Dwyer et al. (1987, p.19) as "an implicit or explicit pledge of relational continuity between partners." Interestingly, Anderson and Weitz (1992) found that commitment is mutually reinforcing and increases over time leading to better benefits in the relationship, while Gundlach et al. (1995) argued that disproportionate commitment between less committed partners can lead to opportunism by the less committed partner. However, Leek, Naudé and Turnbull (2002) demonstrate that suppliers are more concerned about gaining and maintaining the commitment of their customers in the relationship than vice versa. This confirms O'Malley and Tynan's (1997) argument that the existence of one committed party in a relationship does not automatically suggest that all parties in the relationship are committed. Within Et-Moone relationships, commitment must be mutual. The findings from Abosag and Lee (2012, p.607) confirmed that "managers understand that without mutuality they cannot maintain the relationship." Mutual commitment is a cornerstone in the development of an Et-Moone relationship.

In addition, it has been argued that "much of commitment occurs at a personal rather than organizational level” (Rylander, Strutton and Pelton, 1997, p.65). This is particularly true in 
special forms of relationships like Et-Moone which are largely driven by strong personal commitment to the relationship by both partners. The level of commitment in some Et-Moone relationships may be excessive to normal business relationships which, in the Western view of relationships, can be regarded as negative. According to Tellefsen and Thomas (2005), managers think and act as individuals rather than as simple extensions of their organisations. Tellefsen (2002) argued that, because of high personal commitment, managers may engage in unauthorised activities within their own firms to help fulfil their personal obligations to their partner firm's managers. Within Et-Moone relationships, strong commitment is expected and mutually exchanged. Thus the role of interpersonal liking in developing a strong commitment (personal and business commitment) ensures that both partners are developing/can develop their relationships to Et-Moone relationships. Therefore:

H4: strong relationship commitment leads to Et-Moone relationships.

\section{Trust and Et-Moone}

Trust has been defined by Morgan and Hunt (1994, p. 23) as "confidence in the exchange partner's reliability and integrity." Trust has received much attention, primarily because of its influence on partners' long-term orientation (Ganesan, 1994) and its ability to enable partners to assess future behaviour and actions based on past promises and interaction (Doney and Cannon, 1997). Regarding Et-Moone relationships, trust allows Et-Moone's partners the development of greater flexibility and more positive expectations. Similar to normal business relationships, trust in Et-Moone relationships helps diminish ambiguity and any perceived risk of opportunism in the relationship (e.g. Dwyer et al., 1987).

As trust, to some extent, is based on perceived emotion and feelings by individuals about their interaction in terms of security and perceived strength of their relationships (Schurr and 
Ozanne, 1985; Bendapudi and Berry 1997; Johnson and Grayson, 2005), trust that has been derived from interpersonal liking is liable to increase satisfaction (Smith and Barclay, 1997), interdependence (Andaleeb, 1996) and make it possible for partners to consider engaging in Et-Moone relationships. Affective and competence trust were found to be important components of trust that lead to Et-Moone (Abosag and Lee, 2012). Statistically, the relationship between trust and Et-Moone was found to be significant by Abosag and Naudé (2014). Therefore, one can hypothesise:

H5: trust is an important antecedent of Et-Moone relationships.

\section{Et-Moone and Cooperation}

As Et-Moone is the outcome of the combined effect from strong interpersonal liking, commitment and trust, the output of Et-Moone is greater understanding and willingness to share resources for the benefits of one or both sides of the relationship. Hence, Et-Moone results in a greater level of cooperation higher than usually seen in normal cooperation that is based on trust and commitment only in B2B. In normal B2B relationships, as found by Lancastre and Lages (2006), cooperation is positively affected by trust and commitment, termination cost, communication and information exchange, and negatively by product price and opportunism. However, cooperation within Et-Moone relationships is driven almost exclusively by Et-Moone. Because Et-Moone emerges as the result of much higher trust, commitment and liking than in normal B2B, Et-Moone completely removes any opportunism concerns and is directly influenced by the characteristics of Et-Moone.

Cooperation is "the extent to which exchange partners undertake voluntary coordinated action and jointly strive to achieve individual and mutual goals" (Skinner, Gassenheimer and Kelley, 1992). Most coordinated actions within Et-Moone relationships are voluntary. 
However, the cooperative norms within Et-Moone relationships force Et-Moone's partners to feel "obliged to make their resources and power available to each other in order to gain advantages in the market" (Abosag and Naudé, 2014, p. 889). Thus, cooperation is not necessarily aimed at achieving mutual goals as Western literature emphasises (e.g. Anderson and Narus, 1990; Morgan and Hunt, 1994; Ganesan, 1994; Harris and Dibben, 1999; Lancastre and Lages, 2006). The cooperative norms of Et-Moone are mainly structured to: 1) safeguard the relationship from ending; 2) show solidarity and appreciation of the relationship; and 3) provide flexibility, enabling strong responses to changes in the market. This obligation to cooperate and provide support is a distinctive feature of Et-Moone and typically results in greater cooperation in the relationship. Therefore:

H6: Et-Moone allows partners to achieve greater cooperation in the relationship.

Take in Figure 1 here

\section{Methodology}

\subsection{Measure and face validity}

All the scales for all constructs within the model were adopted from existing literature. Interpersonal liking was measured using Nicholson et al.'s (2001) original three measures, complemented by a fourth measure which was added to the scale by Abosag and Naudé (2014). These measures include 'choose to be around this supplier', 'I like my supplier', 'enjoy being with my supplier', and 'I like friendship with my supplier'. The measurements for trust were developed by Doney and Cannon (1997); this scale, containing five measures, reflects the overall trust at the personal and firm levels (has been frank, keeps promises, believes the information from this supplier, no false claims, and trusts this supplier). 
Commitment was measured by adopting four measures from Tellefsen and Thomas (2005). Similar to trust, the measures reflect overall commitment including 'strong sense of loyalty to this supplier', 'expect to deal with this supplier for a long time', 'very committed to this supplier', and 'the relationship with this supplier is a long-term one'. Et-Moone was measured using the five measures developed by Abosag and Naudé (2014) that reflect empathy, gratitude, willingness to do more for the relationship, solidarity, and manifestation of Et-Moone in the relationship. In developing this scale, they used qualitative interviews and tested the scales on senior managers of Saudi manufacturing firms. This scale reflects two important elements of Et-Moone. The first element reflects the felt side of Et-Moone (friendship) by its partners towards their Et-Moone, including strong appreciation and empathy. The second element reflects the behavioural side of Et-Moone (solidarity), including doing things that benefit Et-Moone's partner, willingness to help him/her achieve success in the marketplace and manifestation of Et-Moone in their relationship. On the last element (manifestation), Abosag and Naudé (2014, p. 891) stated Et-Moone partners would have made "clear verbal manifestation of Et-Moone" in their relationship confirming their acceptance and obligations as Et-Moone's partners. Finally, cooperation was measured using the five-measure scale developed by Baker, Simpson and Siguaw (1999), which includes 'problems are joint responsibilities', 'are concerned about the other's profitability', 'will not take advantage of a strong bargaining position', 'both are willing to make cooperative changes', and 'working together to be successful'.

All items were measured on a five-point Likert scale, ranging from 1 (strongly disagree) to 5 (strongly agree). The questionnaire was first written in English and then translated into Arabic. To assess content validity of the measures, the study used the following criteria. 
Firstly, to ensure linguistic equivalence, the back-translation method was used (Brislin, 1986) for the entire questionnaire. This was done using two professional translation agencies in Saudi Arabia. These agencies regularly work with businesses on a daily basis; thus they had more than sufficient experience in translating the scales. The translation started by one of the translation agencies translated the questionnaire from English into Arabic. The author then took the translated version to the second agency who conducted a blind back-translation. The two versions were compared and changes were accordingly made to ensure content/face validity.

Secondly, experts with good experience and in-depth understanding about Saudi Arabian business relationships were asked to evaluate the adequacy of the developed measures alongside the constructs' definitions. Five academics from three Saudi universities acted as judges. Generally, these academics were happy with the scales with the exception of three poor measures which were eliminated as a result. Then a revised questionnaire was pre-tested using a randomly selected sample of over 20 senior managers of industrial companies in Riyadh. Examination of their responses showed a very good understanding of the measures and, after a final refinement from the pre-test, the questionnaire was distributed.

\subsection{Data collection}

The data collection was conducted through a research agency in Saudi Arabia specialising in industrial and service firms. The data collection focused on firms in the three main industrial areas in the capital Riyadh. It involved a face-to-face meeting with the target respondents using a drop-off technique. The number of overall distributed questionnaires was 256. Checking the returned questionnaires resulted in a reduction of 75 questionnaires. This reduced the total of usable questionnaires to 181 , providing a response rate of 70.7 percent, 
which is normal, given the use of the drop-off technique. Because there was a break of about a month in the middle of the data collection, it was necessary to analyse for differences between the early and late data collection. The analysis of the timing of responses showed that no significant differences exist. Finally, the research agency was required to provide the contact details of each respondent, which meant checking on the identity of respondents where possible. This was important to make sure that the target respondents did actually complete the questionnaires and not someone else in their companies. Some of questionnaires that were removed from the data set were completed by either secretaries of CEOs/chairmen or ranked middle managers who were not Saudi Arabian nationals but were from other Arabic countries.

In addition to this and in order to ensure that the data collected reflect the right sample (discussed below), the questionnaire contained screening questions that enabled filtering of the sample. For example, respondents were asked if they have an exciting Et-Moone relationship with any of their suppliers. Those who did not have an Et-Moone relationship were asked not to complete the questionnaire. Another example is by asking respondents to indicate their nationality. Any respondent indicating any other nationality than Saudi Arabian were excluded from the data. Furthermore, the questionnaire was structured to provide: 1) information on the relationship, e.g. firm size, length of the relationship, type of exchange in the relationship, etc.; 2) scale measures were positioned in the middle part of the questionnaire; and 3) information on the respondents themselves such as age, gender and position. 


\subsection{The sample}

The sample consists of 100 percent Saudi nationals who were owners/chairmen (4.9 percent), managing directors (70.2 percent) or purchase managers (24.9 percent). The respondents were asked to identify their main supplier and were asked to relate all of their answers to this main supplier of their firms. The companies were involved in industrial products (61.6 percent), consumer products (25.2 percent), and services (11.3 percent). In terms of firm size in Saudi Arabia respectively, 29 percent of the firms had 100-200 employees, 34.7 percent of the firms had 201-500 employees, and 36.3 percent had over 500 employees.

The size of the supplier, in relation to the size of the responding firm in Saudi Arabia respectively, is smaller (16.1 percent), similar (20.8 percent), and bigger (63.1 percent). The length of the relationship between the firm and its supplier in Saudi Arabia has been: less than five years (13.4 percent), less than ten years (44.8 percent), less than fifteen years (27.6 percent), less than twenty years (8.2 percent), and over twenty years (6 percent). Respondents' average age in Saudi Arabia is 35. All respondents were male and have been in their management position for an average of nine years. All of these indicate that respondents are well qualified to address the focus under consideration and that they are directly involved in managing the special relationship with their business partner.

\section{Statistical Methods and Construct Validation}

All constructs in the model were operationalised using multi-item scales. Table 1 below shows the scales, the factor loadings and composite reliability. In order to ensure that the statements are appropriate for testing the hypotheses, rigorous assessment of validity and reliability was carried out. Validity assessment was conducted using LISREL 8.8. Employing this technique enables statistical efficiency in testing of multiple relationships amongst 
constructs simultaneously (Hair, Anderson, Tatham and Black, 2009). The composite reliability (CR) and average variance extracted (AVE) were calculated for all constructs, and all were above the threshold of .60 for CR (Fornell and Larcker, 1981) and .50 for AVE (Hair et al., 2009).

Finally, discriminant validity was first assessed by using the exploratory factor analysis method. All items were loaded where they were supposed to load, with the exception of only one item - Et-Moone - which has a very minor cross-loading of .407 with one item from commitment. This cross-loading is judged minor and the analysis has proved discriminant validity to exist. In addition to this, discriminant validity was tested for by using Fornell and Larcker's (1981) method. Discriminant validity is judged to exist if the shared variance between two constructs is compared with the AVE for each construct in the model. If the AVE is greater than the shared variance, there is evidence of discriminant validity. As can be seen from Table 2, the AVE for each construct is greater than the squared correlations between such a construct and other constructs, providing evidence of discriminant validity. Furthermore, and in order to show more discriminant validity as suggested by Anderson and Gerbing (1982), the study performed unidimensionality tests for all constructs. All indicators of fit $\chi 2(d f), p$-value, GFI, AGFI and RMSEA show a reasonably good fit for all constructs, thus showing evidence of construct unidimensionality which is further evidence for discriminant validity.

Take in Table 1 here 
Table 2 shows the mean, standard deviation and correlation matrix. Based on all of the analyses we believe the measures are strong enough from a psychometric perspective to be used in the test of the hypotheses. With these solid results, the model was estimated.

Take in Table 2 here

\section{Results}

The suggestion of $\mathrm{Hu}$ and Bentler (1999) for the structural model has been widely implemented by many studies. Thus the incremental fit measures used were CFI and IFI (greater than .90). For absolute fit measures, $\chi^{2}$ statistic, RMSEA (less than .06), GFI and AGFI (greater than .90) were all used. All the hypotheses within the structural model were tested. The estimation of the model resulted in a very good fit $\chi^{2}(\mathrm{df})=8.05(4), \mathrm{p}$-value $=$ $.092, \mathrm{GFI}=.98, \mathrm{AGFI}=.93, \mathrm{IFI}=.99, \mathrm{CFI}=.98, \mathrm{RMSEA}=0.074$. All indices show a good fit; however, RMSEA is slightly above the recommended level but this result is deemed acceptable. Table 3 below shows the estimation of the model. In order to validate the model and to prove the importance of Et-Moone in B2B in Saudi Arabia, a rival model was tested. In the rival model, Et-Moone was removed from the model. This was done because trust and commitment have been repeatedly found to lead to cooperation in Western literature (e.g. Mogan and Hunt, 1994). While it is expected the rival model, as proved in the literature in normal $\mathrm{B} 2 \mathrm{~B}$ relationships, will have a good or acceptable fit, it is important to compare the two models in order to show the importance of Et-Moone in B2B relationships in Saudi Arabia. However, the estimation of the rival model shows a much poorer fit compared to the original model. The estimation of the rival model resulted in $\chi^{2}(\mathrm{df})=9.04(2)$, p-value $=$ $.029, \mathrm{GFI}=.98, \mathrm{AGFI}=.90, \mathrm{IFI}=.95, \mathrm{CFI}=.94, \mathrm{RMSEA}=0.119$. 


\section{Take in Table 3 here}

The results from the estimation of the theoretical model clearly show good for all hypotheses in the model. As predicated, interpersonal liking has the greatest and most significant influence in the model. Interpersonal liking increases commitment in the relationship, significantly achieving the highest coefficient in the model (H3: $\beta=.494 p<.01)$. This is followed by the coefficient between interpersonal liking and trust, $(\mathrm{H} 2: \beta=.421, p<.01)$. The third highest coefficient is also from interpersonal liking to Et-Moone $(\mathrm{H} 1: \beta=.234, p<.05)$. The result shows also that commitment has a stronger impact on Et-Moone (H4: $\beta=.210, p$ <.05). Trust has also a significant impact on Et-Moone (H1: $\beta=.141, p<.10)$. These two results from commitment and trust on Et-Moone clearly show commitment to influence Etmoone stronger than trust. Finally, Et-Moone increases cooperation in the relationship quite strongly $(\mathrm{H} 1: \beta=.202, p<.05)$. The above results confirm the soundness of the theoretical model.

\section{Findings and Discussion}

Prior research that has explored Et-Moone relationships suggested interpersonal liking to be a major driving force behind the development of Et-Moone relationships as well as commitment and trust that tend to exist in most B2B relationships (Abosag and Lee, 2012). The combined effects from these three major antecedents allow managers to be somewhat excessive in their implicit and explicit promises more than they would usually do in normal B2B relationships. This personal dedication and speciality of the relationship escalate cooperation to a much higher level normally not seen in B2B in Anglo-Saxon countries. 
Because Et-Moone relationships make a difference to the competitiveness of partners within the relationships, the value of engaging in such a relationship is undoubtedly attractive.

The findings from this study reinforce previous suggestions and findings from prior studies (Abosag and Lee, 2012; Abosag and Naudé, 2014) in that interpersonal liking is the key driver of Et-Moone relationships. This finding, together with previous findings on the relationship between these two constructs, confirms that, without strong interpersonal liking in the relationship, Et-Moone relationships would never exist. The role of interpersonal liking is more influential when interpersonal liking in the relationship directly affects the nature and level of trust and commitment in the relationship.

The relationship between interpersonal liking and trust was found to be significant. While this is not surprising given the already existing similar findings from Nicholson et al. (2001) and Abosag and Naudé (2014), this finding contradicts the finding by Hawke and Heffernan (2006) who found that trust leads to interpersonal liking. Although Hawke and Heffernan (2006) acknowledged that interpersonal liking may lead to trust, they argued that it is more appropriate that trust leads to interpersonal liking. Within the context of Et-Moone relationships, trust that is based on strong interpersonal liking is more important to Et-Moone relationship development than trust that is not based on interpersonal liking. Future research can certainly examine the impact of trust on interpersonal liking in normal B2B relationships but it is argued that, in special forms of relationships, trust is an outcome of interpersonal liking.

The findings show that the weakest relationship in the theoretical model exists between trust and Et-Moone. Although this relationship is significant, trust has the lowest impact on Et- 
Moone. Explanation of this may be related the fact that Et-Moone as a concept is, as shaped by the cultural and tribal heritage, more of future orientation than current or past orientation. Thus, it is not surprising to find commitment to influence Et-Moore greater than trust.

This study is the first to statistically examine the relationship between interpersonal liking and commitment in the field of industrial marketing. This relationship is found to be the strongest in the model reflecting the importance of interpersonal liking in developing the strong commitment needed for developing Et-Moone in B2B relationships. A strong commitment is essential to the development of Et-Moone. Partners on both sides of the relationship are very unlikely to even consider Et-Moone in their relationship without a previous strong commitment to each other and to the relationship. Within the context of this study, such a strong commitment would only exist if a reasonable level of interpersonal liking has been well developed in the relationship.

Once Et-Moone exists in the relationship, the cooperative aspects of the relationship were predicted to excessively increase. The findings from this study found Et-Moone in B2B relationships generates greater cooperation in the relationship. This suggests that partners are a lot more willing to volunteer to do more for their relationship. Et-Moone provides partners with the flexibility, security and space to request and expect greater cooperation. Abosag and Lee (2012) suggested that, because of Et-Moone in the relationships, partners may even use each other's resources and strength without prior permission to gain an advantage or to cope with difficulties in the market.

Overall, the findings provided good support to the theoretical model. The study is the first to test the relationship between interpersonal liking and commitment, from commitment to Et- 
Moone and from Et-Moone to cooperation. Thus, the contributions from this study are significant and will substantially help future research to advance this area of research.

\section{Managerial Implications}

The findings contain a great deal of implications for managers. These implications are primarily concerned with the best way that managers can develop Et-Moone in their B2B relationships. First, and for most, managers need to think differently when aiming at developing Et-Moone relationships. The mind-set for Et-Moone relationships is different from that in normal B2B relationships. Managers need to think about their own level of personal likeability, which can be achieved by excessive but necessary responses in kind to all the demands and needs of their business partners and delicate management of their interaction, both personal and business alike.

Second, the development of interpersonal liking will naturally take time and managers should be aware of the amount of investment in terms of time needed. However, managers need to be careful of over personalisation of everything in the interaction as this may lead to disliking the entire interaction. Thus, balanced and gradual liking is likely to be stronger over time.

Third, the best way to make sure the right interpersonal liking is developed is for managers to try to increase their attraction in the relation by both professional and personal competences. Managers are advised to focus more on the professionalism of their interaction while responding kindly and appreciatively to aspects of the relationship. It is advisable and safer for managers to let their business partner initiate the personalisation of their interaction. 
Fourth, once a good deal of interpersonal liking exists in the relationship, managers need to understand that trust that is based on their own business competence will always remain important. However, managers need to know that, with a high level of interpersonal liking in the relationship, trust and commitment will increasingly be based more on their interpersonal liking. This is a process that will occur by itself and managers do not need to actively try to influence it.

Fifth, managers need to know that the combined effects from interpersonal liking, trust and commitment will make way for the gradual development of Et-Moone in their relationships. However, it is best for managers not to be the first to use the term 'Et-Moone' in their interaction but rather leave this to be initiated by their business partner, especially if the balance of power in the relationship is in the hands of their partner. Once their partner uses the term 'Et-Moone' in the relationship, this can be taken as a clear announcement by their partner diminishing any aspect of power and opening the relationship to greater cooperation and close personal coordination.

Sixth, managers must understand that reaching the Et-Moone stage is only the beginning for a long-term relationship based on putting your partner's business interests ahead of yours and vice versa. Scarifying for the relationship and taking a risk on behalf of the business partner is expected and must be welcomed. Mutuality is not a necessity but a return, not of the exact nature of the favour but whatever is needed for the partner, should be expected.

Finally, managers who reach an Et-Moone relationship will by this stage have developed a deep understanding of expectations and management of the relationship which they all feel happy with. This does not mean that these expectations will be exactly the same across all Et- 
Moone relationships as every Et-Moone relationship is different, but almost all will result in greater cooperation and coordination of efforts.

\section{Future Research}

While this study has provided a good overall examination of relationships between constructs in the model, future research may need to differentiate between the already-existing commitment to the $\mathrm{B} 2 \mathrm{~B}$ relationship and the escalated commitment as a result of strong interpersonal liking that makes Et-Moone possible in the relationship. It is acknowledged that isolating the effects of constructs like trust and commitment in normal B2B relationships from the effects of these constructs during Et-Moone relationships is very difficult. However, future studies may compare normal B2B relationships with an Et-Moone relationship with the aim of adding further understanding of the nature and effects of the main three antecedents, namely interpersonal liking, trust and commitment. This is particularly important given that the result from testing the rival model, within which Et-Moone was removed, shows that the rival model has a much poorer fit. It is usually found that trust and commitment influence cooperation in normal B2B. Therefore, future studies can add significant contributions by comparing normal B2B relationships with Et-Moone relationships.

Clearly, Et-Moone is valuable to B2B relationships. Despite the few studies that have already explored the concept of Et-Moone, attention must be focused on how to develop and maintain Et-Moone in B2B relationships. This study has provided a good examination of the key antecedents of Et-Moone and its impact on only one construct, namely cooperation. Future research should examine the impact of Et-Moone on performance-related constructs and competitiveness of partners of Et-Moone. This will be a significant contribution to our understanding of Et-Moone relationships. 
In addition, future research should investigate the impact of Et-Moone relationships within business network, especially on how such relationship influences the dynamic of a business network. Furthermore, closer examination of how Et-Moone relationships creates and maintains unique value in the relationship needs to receive some attention. This can also be extended to the area of value co-creation within Et-Moone relationships.

Finally, this study tested Et-Moone using an overall scale that combined its underlying dimensions of 'felt Et-Moone' and 'behavioral Et-Moone'. Future studies should consider testing the relationship between the antecedent constructs (interpersonal liking, trust and commitment) and both 'felt Et-Moone' and 'behavioral Et-Moone'. In addition, it would be beneficial if future studies also tested these dimensions of Et-Moone on output constructs such as cooperation, performance, satisfaction, etc. 


\section{References:}

Abdul-Muhmin, A. (2002). Effects of suppliers' marketing program variables on industrial buyers' relationship satisfaction and commitment. Journal of Business \& Industrial Marketing, 17(7), 637-651.

Abdul-Muhmin, A. (2005). Instrumental and interpersonal determinants of relationship satisfaction and commitment in industrial markets. Journal of Business Research, $58(5), 619-628$.

Abosag, I. and Naudé, P. (2014). Development of special forms of B2B relationships: Examining the role of interpersonal liking in developing Guanxi and Et-Moone relationships. Industrial Marketing Management, 43(6), 887-896.

Abosag, I. and Lee, J. (2012). The formation of trust and commitment in business relationships in the Middle East: Understanding Et-Moone relationships. International Business Review, 21(6), 602-614.

Andaleeb, S. (1996). An experimental investigation of satisfaction and commitment in marketing channels: the role of trust and dependence. Journal of Retailing, 72 (1), $77-$ 93.

Anderson, E. and Weitz, B. (1992). The use of pledges to build and sustain commitment in distribution channels. Journal of Marketing Research, 29(1), 18-35.

Anderson, J. and Gerbing, D. (1982). Some methods for respecifying measurement models to obtain unidimensional construct measurement. Journal of Marketing Research, 19 (November), 453-460.

Anderson, J. and Narus, A. (1990). A model of distributor-firm and manufacturer-firm working partnerships. Journal of Marketing, 54 (1), 42-58. 
Baker, T, Simpson, P. and Siguaw, J. (1999). The impact of suppliers' perceptions of reseller market orientation on key relationship constructs. Academy of Marketing Science Journal, 27(1), 50-57.

Bendapudi, N. and Berry, L. (1997). Consumer's motivations for maintaining relationships with service providers. Journal of Retailing, 73(1), 15-38.

Bhuian, S. (1998). An empirical examination of market orientation in Saudi Arabian manufacturing companies. Journal of Business Research, 43(1), 13-25.

Brislin, R. (1986). The wording and translation of research instruments. In Lonner, W. and Berry, J., Field Methods in Cross-Cultural Research, Sage Publication, London, pp. $137-164$.

Chen, Z., Huang, Y. and Stemquist, B. (2011). Guanxi practice and Chinese buyer-supplier relationships: The buyer's perspective. Industrial Marketing Management, 40(4), 569580.

Crosby, L., Evans, K. and Cowles, D. (1990). Relationship quality in services selling: an interpersonal perspective. Journal of Marketing, 54 (3), 68-81.

Doney, P. and Cannon, J. (1997). An examination of the nature of trust in buyer-seller relationships. Journal of Marketing, 61(2), 35-52.

Dwyer, F. Schurr, P. and Oh, S. (1987). Developing buyer-seller relationships. Journal of Marketing, 51(2), 11-27.

Fornell, C. and Larcker, D. F. (1981). Evaluating structural equation models with unobservable variables and measurement error. Journal of Marketing Research, 28(1), $39-50$.

Ganesan, S. (1994). Determinants of long-term orientation in buyer-seller relationships. Journal of Marketing, 58(2), 1-19. 
Gundlach, G., Achrol, R. and Mentzer, J. (1995). The structure of commitment in exchange. Journal of Marketing, 59(1), 72-92.

Hair, J., Anderson, R., Tatham, R. and Black, W. (2009). Multivariate Data Analysis. $7^{\text {th }}$ Ed., New Jersey: Prentice-Hall.

Harris, L., O’Malley, L. and Patterson, M. (2003). Professional interaction: exploring the concept of attraction. Marketing Theory, 3(1), 9-36.

Harris, S. and Dibben, M. (1999). Trust and co-operation in business relationship development: exploring the influence of national values. Journal of Marketing Management, 15(6), 463-483.

Hawke, A. and Heffernan, T. (2006). Interpersonal liking in lender-customer relationships in the Australian banking sector. International Journal of Bank Marketing, 24 (3), 140157.

Hu, L. and Bentler, P. (1999). Cut-off criteria for fit indexes in covariance structure analysis: Conventional criteria versus new alternatives. Structural Equation Modelling, 6 (1), $1-55$.

Johnson, D. and Grayson, K. (2005). Cognitive and affective trust in service relationships. Journal of Business Research, 58(4), 500-507.

Lancastre, A. and Lages, L.F. (2006). The relationship between buyer and a B2B emarketplace: Cooperation determinants in an electronic market context. Industrial Marketing Management, 35 (Sept), 774-789.

Leek, S., Naudè, R. and Turnbull, P. (2002). Managing business-to-business relationships: an emerging model. Proceedings of the $18^{\text {th }}$ IMP Conference, Dijon, France. 
Liu, Y., Li, Y., Tao, L. and Wang, Y. (2008). Relationship stability, trust and relational risk in marketing channels: Evidence from China. Industrial Marketing Management, $37(3), 432-446$.

Lohtia, R., Bello, D. and Porter, C. (2009). Building trust in US-Japanese business relationships: Mediating role of cultural sensitivity. Industrial Marketing Management, 38(3), 239-252.

Luo, Y. (2007). Guanxi and Business. Singapore: World Scientific Publishing Co Ltd.

Michailova, S. and Worm, V. (2003). Personal networking in Russia and China: Blat and Guanxi. European Management Journal, 21(4), 509-519.

Morgan, R. and Hunt, S. (1994). The commitment-trust theory of relationship marketing. Journal of Marketing, 58(3), 20-38.

Nicholson, C., Compeau, L. and Sethi, R. (2001). The role of interpersonal liking in building trust in long-term channel relationships. Academy of Marketing Science Journal, $29(1), 3-15$.

O’Malley, L. and Tynan, C. (1997). A reappraisal of the relationship marketing constructs of commitment and trust. The AMA Relationship Marketing Conference, Dublin, Ireland.

Pimpa, N. (2008). Relationship value in Thai business-to-business marketing. Journal of Asia-Pacific Business, 9(3), 235-247.

Robbins T. and DeNisi A. (1994). Interpersonal affect and cognitive processing in performance appraisal: towards closing the gap. Journal of Applied Psychology, 79, 341-350.

Rylander, D., Strutton, D. and Pelton, L. (1997). Toward a synthesized framework of relational commitment: implications for marketing channel theory and practice. Journal of Marketing Theory and Practice, 5(2), 1-14. 
Schurr, P. and Ozanne, J. (1985). Influences on exchange processes: buyer's preconceptions of a seller's trustworthiness and bargaining toughness. Journal of Consumer Research, 11(4), 939-953.

Skinner, S., Gassenheimer, J. and Kelley, S. (1992). Cooperation in supplier-dealer relations. Journal of Retailing, 68(2), 174-193.

Smith, J and Barclay, D. (1997). The effects of organisational differences and trust on the effectiveness of selling partner relationships. Journal of Marketing, 61(1), 3-21.

Styles, C. and Ambler, T. (2003). The coexistence of transaction and relational marketing: Insights from the Chinese business context. Industrial Marketing Management, 32(3), $633-642$.

Tellefsen, T. (2002). Commitment in business-to-business relationships. Industrial Marketing Management, 31(8), 645-652.

Tellefsen, T. and Thomas, G. (2005). The antecedents and consequences of organisational and personal commitment in business service relationships. Industrial marketing management, 34(1), 23-37.

Thunman, Carl G. (1992). Corporate Banking: Services and Relationships. International Journal of Bank Marketing, 10 (2), 10-16.

Weitz, B. and Jap, S. (1995). Relationship marketing and distribution channels. Journal of the Academy of Marketing Science, 23(4), 305-320.

Wilson, D. (1995). An integrated model of buyer-seller relationships. Journal of the Academy of Marketing Science, 23(4), 335-346. 
Zaheer, A., McEvily, B. and Perrone, V. (1998). Does trust matter? Exploring the effects on interorganisational and interpersonal trust on performance. Organisation Science, $9(2), 141-159$.

Zajonc, R. (1980). Feeling and thinking: preferences need no inferences. American Psychologist, 35(2), 151-175.

Zhuang, G., Xi, Y. and Tsang, A.S.L. (2010). Power, conflict and cooperation: The impact of guanxi in Chinese marketing channels. Industrial Marketing Management, 39(1), $137-149$. 